Avi-Dor, Y., Kuczynski, M., Schatzberg, G. \& Mager, J. (1956). J. gen. Microbiol. $14,76-83$

\title{
Turbidity Ghanges in Bacterial Suspensions: Kinetics and Relation to Metabolic State
}

\author{
BY Y. AVI-DOR, MIRIAM KUCZYNSKI, GISELA SCHATZBERG \\ AND J. MAGER* \\ Israeli Institute for Biological Research, Ness-Ziona, Israel
}

\begin{abstract}
SUMMARY: The kinetics of the turbidity changes in bacterial suspensions due to variations in the osmotic pressure of the medium were investigated. The time curve of the turbidity changes followed a monomolecular course, but the velocity constant was strongly dependent on the osmotic pressure. The value of the temperature coefficient $\left(Q_{10}\right)$ of the reaction was close to two. The rapid adjustment of the turbidity (increase or decrease) to the changes in osmotic pressure of the medium was followed by a phase of slow decline in light extinction. In this slow phase the rate of turbidity decrease was independent of the prevailing osmotic pressure, but varied with the nature of the solute used; it was markedly accelerated by $\mathrm{KCN}$ or $\mathrm{HgCl}_{2}$. The effect of $\mathrm{HgCl}_{2}$ was annulled by thiol compounds. Certain substances affected the optical effect and the respiration in a parallel manner. The similarity between these observations and the findings of several authors with regard to turbidity changes in mitochondrial suspensions is discussed.
\end{abstract}

It has been shown in the preceding communication (Mager, Kuczynski, Schatzberg \& Avi-Dor, 1956) that changes in the osmotic pressure of the medium elicited corresponding changes in the turbidity of suspensions of Gram-negative micro-organisms. This optical effect (o.E.) was tentatively attributed to changes in the state of swelling of the bacterial cytoplasm. The present study presents some further observations, which have a bearing on the nature of this phenomenon.

\section{METHODS}

'The chemicals, micro-organisms and the experimental procedures employed were the same as described before (Mager et al. 1956). The conditions of ultraviolet irradiation are indicated in the text. For dry weight determination, the centrifuged bacterial mass was dried in a vacuum oven at $60^{\circ}$ to constant weight. For kinetic studies, the Beckman spectrophotometer model D.U. equipped with a thermospacer for temperature control, was used.

\section{RESULTS}

Fig. 1 illustrates the kinetics of turbidity changes in suspensions of Pasteurella tularensis (strain S \& D) elicited by different mono-monovalent electrolytes, possessing either a common cation or common anion. The increase in turbidity, due to changes in the osmotic pressure of the suspending medium, proceeded

\footnotetext{
* Present address: Department of Biochemistry, The Hebrew University, Hadassah
} Medical School, Jerusalem. 
at a quick, but still measurable rate (phase I), which differed only slightly for the various mono-monovalent salts tested. After the maximum turbidity had been reached, the light extinction declined slowly with the time (phase II). The rate of decrease in the optical density was strongly dependent on the nature of the solute used, being especially rapid with ammonium acetate. Both the ammonium and the acetate ions are known to be highly diffusible through biological membranes (Jakobs, 1940).

The effect of the solute concentration on the rate of the turbidity changes was studied with $\mathrm{MgCl}_{2}$ for phase I (ascending branch), and with potassium acetate for phase II (descending branch), the convenient rates of turbidity changes obtained with these solutes facilitating accurate measurements.

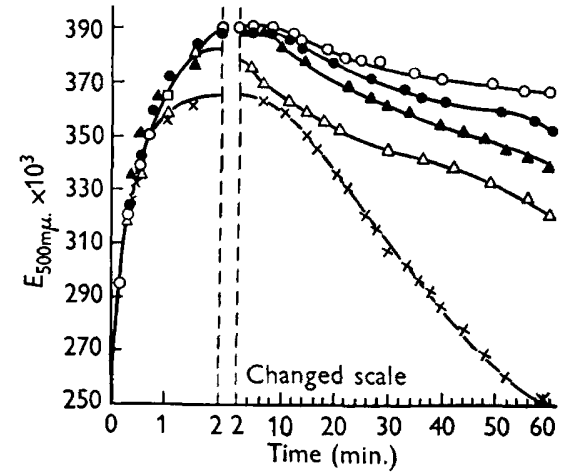

Fig. 1

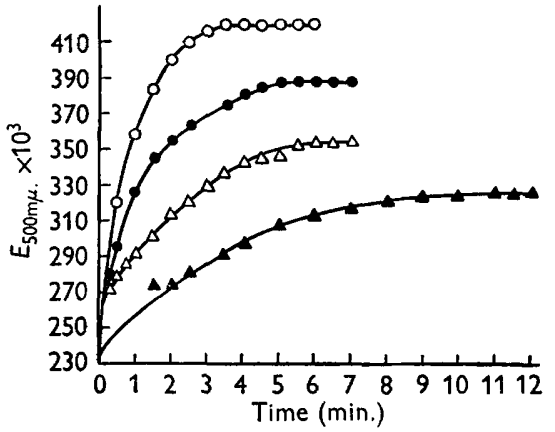

Fig. 2

Fig. 1. Kinetics of turbidity changes. Each Beckman cell contained $15 \mu$ mole solute in a total volume of $3.0 \mathrm{ml}$.; $0.1 \mathrm{ml}$. of a suspension of Pasteurella tularensis (24 hr. culture) in distilled water was added at zero time. $\bigcirc-\mathrm{O}, \mathrm{NaCl} ;-\longrightarrow, \mathrm{KCl} ; \triangle-\triangle, \mathrm{NH}_{4} \mathrm{Cl}$; $\Delta-\Delta \mathrm{KNO}_{3} ; \times-\times$, ammonium acetate.

Fig. 2. Effect of solute concentration on the rate of turbidity changes. Each cell contained $\mathrm{MgCl}_{2}$ in the concentrations indicated; total volume $3.0 \mathrm{ml}$. The reaction was started by the addition of $0.1 \mathrm{ml}$. Pasteurella tularensis (S \& D) suspension. $\mathbf{A}-\mathbf{\Delta}, 0.033 \mathrm{M}-\mathrm{MgCl}_{2}$; $\triangle-\triangle, 0 \cdot 066 \mathrm{M}$

$0 \cdot 132 \mathrm{~m} ; \mathrm{O}-\mathrm{O}, 0 \cdot 264 \mathrm{M}$.

It can be seen from Fig. 2 that for each solute concentration the rate of change decreased gradually, when the maximum value of the turbidity change $\left(\boldsymbol{E}_{m}^{\prime}\right)$ was approached, while the slope of the curves became steeper with increasing $\mathrm{MgCl}_{2}$ concentrations. Plotting of the curves on a semi-logarithmic scale yielded straight lines, thus indicating that the rate of change follows a first-order reaction course. Assuming that under otherwise constant conditions the rate of change at any instant $\left(\mathrm{d} E^{\prime}\right)$ is proportional to $E_{m}^{\prime}-E_{t}^{\prime}$ (where $E_{t}^{\prime}$ is the turbidity change at time $t$; cf. first part of this communication), the following equation can be derived:

or, in its integrated form,

$$
\frac{\mathrm{d} \boldsymbol{E}^{\prime}}{\mathrm{d} \boldsymbol{T}}=k_{1}\left(\boldsymbol{E}_{m}^{\prime}-\boldsymbol{E}_{t}^{\prime}\right)
$$

$$
k_{1}=\frac{1}{t} \ln \frac{E_{m}^{\prime}}{E_{m}^{\prime}-E_{t}^{\prime}} .
$$




\section{Y. Avi-Dor, M. Kuczynski, G. Schatzberg and J. Mager}

The experimental data for any solute concentration fit this equation well. The velocity constant $k_{1}$, however, increases as a function of $\boldsymbol{E}_{m}$ (Table 1) contrary to what would be expected for a first-order reaction. Moreover, the rate of turbidity changes elicited by solutes applied in 'optically equivalent'

Table 1. Correlation between the concentration of the solute, the maximal turbidity change $\left(E_{m}^{\prime}\right)$ and the velocity constant $\left(k_{1}\right)$

$\begin{array}{ccc}\begin{array}{c}\text { Concentration } \\ \text { of } \mathrm{MgCl}_{2} \\ \left(\mathrm{M} \times 10^{-2}\right)\end{array} & E_{m}^{\prime} & k_{1} \times 10^{3} \mathrm{sec}^{-1} \\ 3 \cdot 3 & 0 \cdot 090 & 1 \cdot 70 \\ 6 \cdot 6 & 0 \cdot 117 & 4 \cdot 85 \\ 13 \cdot 2 & 0 \cdot 151 & 11 \cdot 2 \\ 26 \cdot 4 & 0 \cdot 183 & 13 \cdot 4\end{array}$

concentrations (i.e. producing the same o.E.) differed for mono-monovalent electrolytes on the one hand and for $\mathrm{MgCl}_{2}$ and glucose on the other (Fig. 3). Fig. 4 shows that in contrast to the rapid phase, the rate of turbidity changes in the slow descending phase $\left(k_{2}\right)$ is nearly linear and independent of the solute concentration.

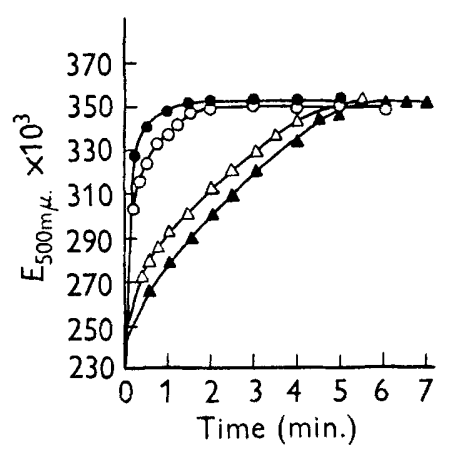

Fig. 3

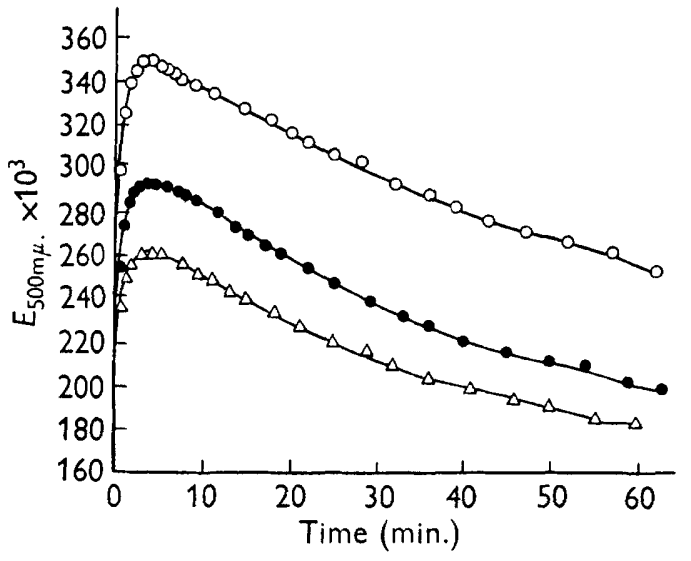

Fig. 4

Fig. 3. The velocity of turbidity changes produced by different solutes. Each cell contained the solute in the concentration indicated; total volume $3.0 \mathrm{ml}$. The reaction was started by the addition of $0.1 \mathrm{ml}$. of an aqueous suspension of Pasteurella tularensis (S \& D). $-\mathrm{NaCl} 0.066 \mathrm{M} ; \bigcirc-\bigcirc, \mathrm{KCl} 0.066 \mathrm{M} ; \Delta-\Delta$, glucose $0.066 \mathrm{M} ; \triangle-\triangle, \mathrm{MgCl}_{2} 0.033 \mathrm{M}$.

Fig. 4. The effect of solute concentration on rate of decrease in turbidity. Each cell contained potassium acetate in the concentrations indicated; total volume $3.0 \mathrm{ml}$. The reaction was started by the addition of $0.1 \mathrm{ml}$. of Pasteurella tularensis (S \& D) suspension. $\bigcirc-O, 0 \cdot 264 \mathrm{M} ;-0.132 \mathrm{M} ; \triangle-\triangle, 0.066 \mathrm{M}$.

\section{Effect of temperature and $\mathrm{pH}$ value}

$Q_{10}$ for $k_{1}$ was found to be approximately 2 with either $\mathrm{NaCl}$ or glucose. Both $E_{m}^{\prime}$ and the rate constants $k_{1}$ and $k_{2}$ showed no dependence on $\mathrm{pH}$ value between $\mathrm{pH} 6$ and 8 . 


\section{Effect of $\mathrm{HgCl}_{2}$ and $\mathrm{KCN}$}

It can be seen from Fig. 5 that $\mathrm{HgCl}_{2}$ and $\mathrm{KCN}$ used in concentrations which were found to inhibit the respiration of Pasteurella tularensis (strain S \& D) accelerated considerably the rate in the descending part of the turbidity change-time curves $\left(k_{2}\right)$. If a suspension of this micro-organism was incubated for $1 \mathrm{hr}$. at $37^{\circ}$ with these substances and then tested for the o.E., the influence of $\mathrm{HgCl}_{2}$ on $k_{2}$ became even more pronounced, while that of $\mathrm{KCN}$ remained unchanged. The action of $\mathrm{KCN}$ could be reversed by washing the bacteria, while for the reversal of the effect of $\mathrm{HgCl}_{2}$, incubation with a thiol compound was required (Fig. 6).

Incubation of suspensions of Escherichia coli with $\mathrm{HgCl}_{2}\left(5 \times 10^{-5} \mathrm{M}\right.$, $\left.1 \mathrm{hr} .-37^{\circ}\right)$ inhibited the o.E. completely. When these cells were subsequently washed with thiomalate $\left(5 \times 10^{-2} \mathrm{M}\right)$ and resuspended in water, the o.E. was restored to about $80 \%$ of the original value.

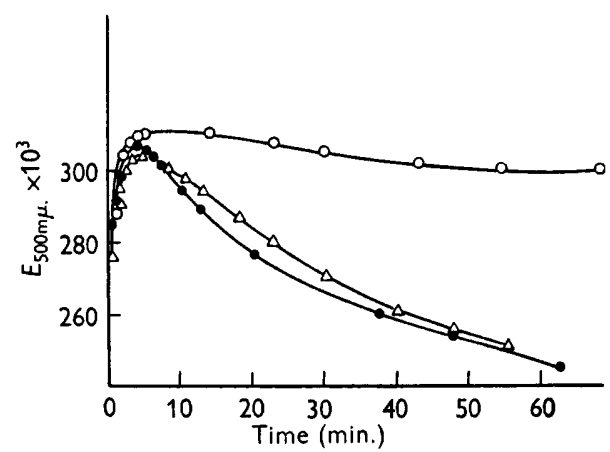

Fig. 5

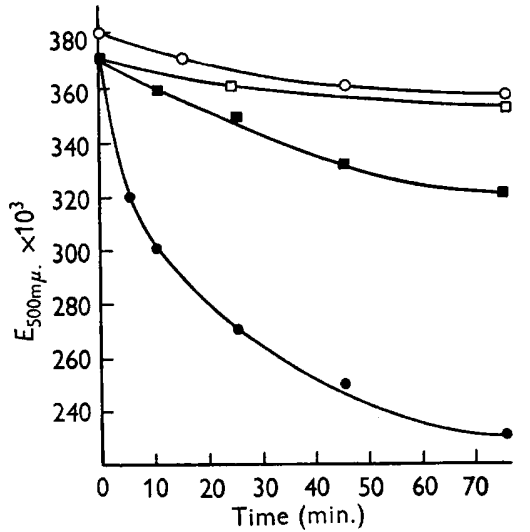

Fig. 6

Fig. 5. Effect of $\mathrm{KCN}$ and $\mathrm{HgCl}_{2}$ on the velocity of turbidity changes. Each cell contained $\mathrm{NaCl} 0 \cdot 132 \mathrm{M}$; total volume $3.0 \mathrm{ml}$. $\bigcirc-O$, control; $-0,10^{-2} \mathrm{M}-\mathrm{KCN} ; \triangle-\triangle, 5 \times 10^{-5} \mathrm{M}-$ $\mathrm{HgCl}_{2}$. The reaction was started by the addition of $0.1 \mathrm{ml}$. of an aqueous suspension of Pasteurella tularensis (S \& D) 24 hr. culture.

Fig. 6. The reversal by thiomalate of the decrease of the optical effect induced by mercury chloride. A washed suspension of cells of Pasteurella tularensis (S \& D) was incubated for $1 \mathrm{hr}$. at $37^{\circ}$ with $5 \times 10^{-5} \mathrm{M}-\mathrm{HgCl}_{2}$ and the o.E. measured in one sample with $0 \cdot 132 \mathrm{M}-\mathrm{NaCl}\left(\mathrm{O}-\mathrm{O}\right.$, control ; - $-\mathrm{HgCl}_{2}$-treated cells). Another sample was incubated for $1 \mathrm{hr}$. with $10^{-2} \mathrm{M}$-thiomalate, washed and tested again for the o.E. $\square-\square$, control incubated with thiomalate; $\mathbf{\square -}, \mathrm{HgCl}_{2}$-treated cells after incubation with thiomalate.

\section{Correlation between inhibition of respiration and the abolition of the optical effect}

The above findings suggested a correlation between the inhibitory action of certain compounds on the respiration of bacteria and their effect on turbidity changes. In fact, with $\mathrm{HgCl}_{2}$ (Fig. $7 a$ ) and with chloramine $\mathrm{T}$ (Fig. $7 b$ ) as well as with other respiratory inhibitors (iodoacetate, 2,4-dichlorophenol), the decrease in the o.E. started only after the respiration was strongly inhibited. 


\section{Effect of ultraviolet irradiation}

It was shown previously (Mager et al. 1956) that certain treatments such as exposure to unfavourable $\mathrm{pH}$ values, alternate freezing and thawing, heating etc., produced a parallel decrease in both the viable count and the o.E. Since ultraviolet irradiation, when applied in moderate doses, sterilizes bacterial cultures without affecting their respiration (Errera, 1953), it appeared of
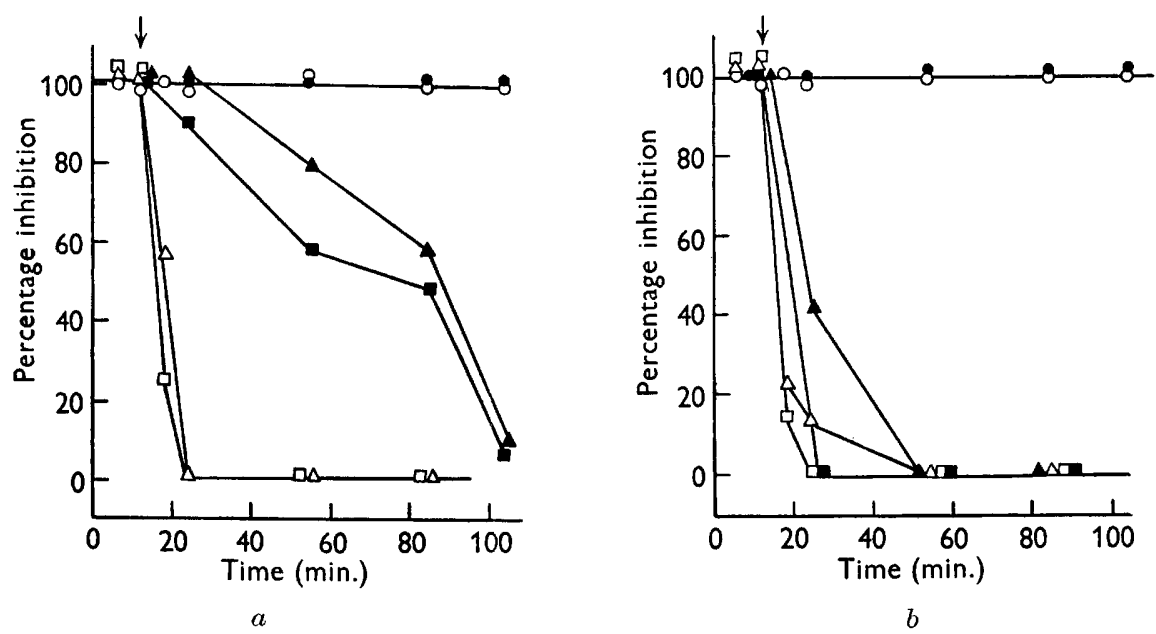

Fig. $7 a, b$. Correlation between the action of inhibitors on the respiration and on the optical effect. Each flask contained $0.5 \mathrm{ml}$. 0.1 M-phosphate buffer $(\mathrm{pH} \mathrm{7 \cdot 4}), 0 \cdot 3 \mathrm{ml}$. 0.1 Msodium pyruvate, and suspension of Escherichia coli (16 hr. culture, $5 \mathrm{mg}$. dry wt.). The final volume was made to $3.0 \mathrm{ml}$. with distilled water. The inhibitor was added from the side arm at the time indicated by the arrow. The centre-well contained $0.2 \mathrm{ml}$. $20 \% \mathrm{KOH}$. o.E. was tested with $\mathrm{NaCl}$. The rates of $\mathrm{O}_{2}$ uptake (unshaded marks) and the o.E. (shaded marks) were expressed in percentage of the values obtained at zero

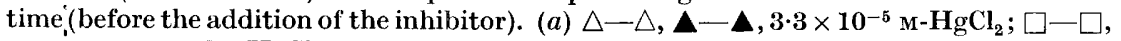
$\square-\mathbf{E}, 6.6 \times 10^{-5} \mathrm{M}-\mathrm{HgCl}_{2} ; \mathrm{O}_{-} \mathrm{O},-\mathrm{O}$, controls. (b) $\triangle-\triangle, \Delta-\Delta, 3 \cdot 3 \times 10^{-4} \mathrm{M}$-chloramine T; $\square-\square, \square-\square, 6.6 \times 10^{-4} \mathrm{M}$-chloramine $\mathrm{T} ; \mathrm{O}-\mathrm{O}, \boldsymbol{0}-\boldsymbol{0}$, controls.

interest to find out how this agent would influence the o.E. In Table 2 the effect of different doses of ultraviolet irradiation on viable count, respiration and the o.E. are compared. It can be seen that an exposure time sufficient for a thousandfold decrease of the viable count had no appreciable effect on the o.E. Only excessive doses of ultraviolet irradiation, which depressed respiration, diminished the o.E. too.

\section{Correlation between the water content of the bacterial cell and the optical effect}

When suspensions of micro-organisms in water and in $\mathbf{0 . 5} \mathrm{M}-\mathrm{NaCl}$ were spun at 16,000 r.p.m. in a Servall angle centrifuge for $1 \mathrm{hr}$. and both the wet and dry weights of the bacterial mass were determined, significant differences were observed in the wet weight/dry weight ratio of the two respective suspensions 
(Table 3). Since the intercellular space, as determined by the inulin method (Conway \& Downey, 1950), was found to be equal in both suspensions, the different ratio seems to be attributable to differences in the water content of the cells. It should be pointed out that Gram-positive species behaved similarly in this respect.

Table 2. Effect of ultraviolet irradiation on the optical effect and viable counts

A suspension of washed Escherichia coli, B/r, $\left(16 \mathrm{hr}\right.$. culture, $\left.E_{w}: 0 \cdot 38\right)$ was exposed in $10 \mathrm{ml}$. batches in $9 \mathrm{~cm}$. diameter Petri dishes to a Claude Lumière ultraviolet lamp type S.500, $50 \mathrm{~cm}$. distant, for various times as indicated. The organisms were separated by centrifugation, washed and resuspended in distilled water.

\begin{tabular}{|c|c|c|c|c|c|}
\hline \multirow[b]{2}{*}{$\begin{array}{c}\text { Irradiation } \\
\text { time } \\
\text { (min.) }\end{array}$} & \multirow[b]{2}{*}{ Plate counts } & \multicolumn{2}{|c|}{ Pyruvate $3 \times 10^{-2} \mathrm{M}$} & \multicolumn{2}{|c|}{ Glutamate $3 \times 10^{-2} \mathbf{M}$} \\
\hline & & $E^{\prime}$ & $\begin{array}{c}Q_{\mathrm{O}_{2}} \\
(\mu 1 . / 60 \mathrm{~min} .)\end{array}$ & $\boldsymbol{E}^{\prime}$ & $\begin{array}{c}\boldsymbol{Q}_{\mathrm{O}_{2}} \\
(\mu 1 . / 60 \text { min. })\end{array}$ \\
\hline 0 & $3 \cdot 3 \times 10^{9}$ & 54 & 440 & 46 & 309 \\
\hline 10 & $3 \cdot 2 \times 10^{3}$ & 48 & 433 & 32 & 219 \\
\hline 20 & $5.5 \times 10^{2}$ & 30 & 217 & 30 & 75 \\
\hline 30 & $2 \cdot 2 \times 10^{2}$ & 20 & 108 & 12 & 35 \\
\hline 45 & 40 & 12 & 57 & 0 & 26 \\
\hline
\end{tabular}

Table 3. Comparison of dry weights of various bacteria sedimented from distilled water and from $0.5 \mathrm{M}-\mathrm{NaCl}(24, \mathrm{hr}$. culture)

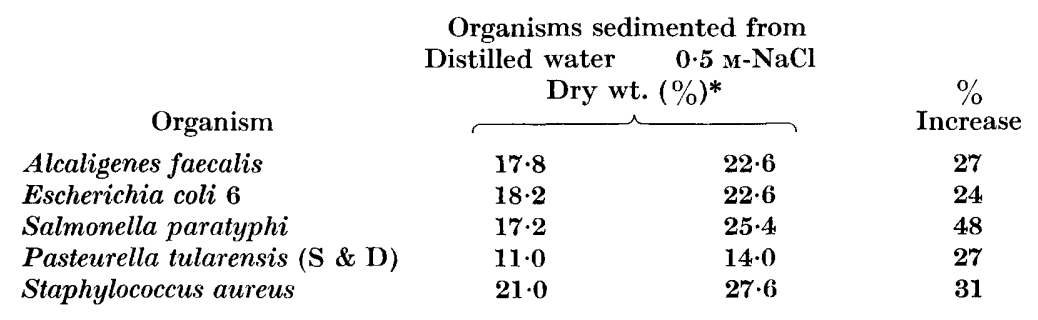

* Dry weight corrected for ash.

\section{DISCUSSION}

Osmotic changes through a non-ideally semipermeable membrane (membranes of living organisms appear to belong to this type) are the resultant of two concurrent reactions: $(a)$ transport of water in the direction opposite to the concentration gradient; $(b)$ diffusion of the solute through the membrane in the direction of the gradient. The maximum volume changes of such a system will thus represent the net result of the two opposing processes.

The curves reflecting the turbidity changes in bacterial suspensions in relation to time (Fig. 1) can be clearly divided into two parts: a rapid phase, followed by a slow decline in light extinction. It is probable that the rapid phase corresponds to volume changes in response to an outward movement of water, whereas the slow phase is due to the readjustment of the cell volume to the gradually decreasing concentration gradient as a result of the inward 
diffusion of the solute. Quite similar turbidity changes were observed in ratheart sarcosomes (mitochondria) by Cleland (1952). The relative permeability factors calculated for $\mathrm{NaCl}$ or $\mathrm{KCl}$ from the slow phase of turbidity changes in sarcosomes are of the same order of magnitude as in Pasteurella tularensis. Turbidity changes in mitochondria due to variation in the state of swelling were also reported recently by other authors (Raaflaub, 1953; Price \& Davies, 1954). It is assumed that the turbidity changes in mitochondria are mainly due to an alteration of the refractive index of the particles (Cleland, 1952). The correlation observed between the wet weight/dry weight ratio of microorganisms and the tonicity of the medium affords added support for the hypothesis that changes in the state of swelling are responsible for the optical effect. The exact nature of these changes is, however, still obscure.

The course of turbidity changes in bacterial suspensions elicited by variations in the osmotic pressure obeys the law of a first-order reaction. The velocity constant $\left(k_{1}\right)$ varies, however, with the solute concentration, as if the membrane permeability itself would depend on the surrounding osmotic pressure. Similar observations were reported by Lucké and co-workers in their studies on the kinetics of volume changes in eggs of Arbacia punctulata induced by varying osmotic pressures (McCutcheon \& Lucke, 1926, 1927). They also noted the anomalously high temperature coefficient of the osmotic process. Later Lucké, Hartline \& McCutcheon (1931) showed that with an improved equation, which takes account of the concomitant changes in the surface area of the cell, the dependence of the rate of swelling on the osmotic pressure can be explained.

As previously reported (Mager et al. 1956), the o.E. is exhibited only by living micro-organisms. The reversible abolition of the o.e. by $\mathrm{HgCl}_{2}$ and the correlation between the effect of certain agents (bactericidal substances, ultraviolet irradiation) on respiration and turbidity changes, indicate that the more direct reason for the disappearance of the o.E. might probably be the decrease of the rate of respiration below a certain critical level. A correlation between the state of swelling and respiration in tissues (Elliot, 1946; Stern, Eggleston, Hems \& Krebs, 1949) and in mitochondria (Macfarlane \& Spencer, 1953; Bartley \& Davies, 1954) has been observed by many authors. The analogous findings in bacteria presented in this paper suggest that a similar mechanism may be involved in regulating the metabolic state of the bacterial cell.

\section{REFERENCES}

Bartley, W. \& Davies, R. E. (1954). Active transport of ions by sub-cellular particles. Biochem. J. 57, 37.

Cleland, K. W. (1952). Permeability of isolated rat heart sarcosomes. Nature, Lond. 170, 497.

Conway, E. J. \& Downey, M. (1950). An outer metabolic region of the yeast cell. Biochem. J. 47, 347.

Euliot, K. A. C. (1946). Swelling of brain slices and the permeability of brain cells to glucose. Proc. Soc. exp. Biol., N.Y. 63, 234.

Errera, M. (1953). Mechanism of biological action of ultraviolet and visible radiation. Prog. Biophys. 3, 88. 
$J_{\text {AKoBs, }}$ M. H. (1940). Some aspects of cell permeability to weak electrolytes. Cold Spr. Harb. Symp. quant. Biol. 8, 30.

Lucké, B., Hartuine, H. K. \& McCutcheon, M. (1931). Further studies on the kinetics of osmosis in living cells. J. gen. Physiol. 14, 405.

McCutcheon, M. \& Lucke, B. (1926). The kinetics of osmotic swelling in living cells. J. gen. Physiol. 9, 697.

McCutcheon, M. \& Lucke, B. (1927). The kinetics of exosmosis of water from living cells. J. gen. Physiol. 10, 659.

Macfarlane, M. G. \& Spencer, A. G. (1953). Changes in the water, sodium and potassium content of rat-liver mitochondria during metabolism. Biochem. J. 54, 569 .

Mager, J., Kuczynski, M., Schatzberg, G. \& Avi-Dor, Y. (1956). Turbidity changes in bacterial suspensions in relation to osmotic pressure and metabolic state. J. gen. Microbiol. 14, 69.

Price, C. A. \& Davies, R. E. (1954). Active transport of water by mitochondria. Biochem. J. 58, xvii.

RAAFLAUB, J. (1953). The swelling of isolated liver cell mitochondria and physicochemical factors influencing their behaviour. Helv. physiol. acta, 11, 157.

Stern, J. R., Eggleston, L. V., Hems, R. \& Krebs, H. A. (1949). Accumulation of glutamic acid in isolated brain tissue. Biochem. J. 44, 410.

(Received 21 July 1955) 